Case Report

\title{
Management of Acute Primary Herpetic Gingivo-stomatitis in Children
}

\author{
Naila Marzuqi, Ali Taqwim, Niken Rahma Vitasari, Tania Saskianti \\ Department of Pediatric Dentistry, \\ Faculty of Dental Medicine, Universitas Airlangga \\ Surabaya - Indonesia
}

\begin{abstract}
Background: Acute primary herpetic gingivostomatitis is the symptomatic presentation of the initial exposure to the herpes simplex virus 1 (HSV-1). The clinical condition of acute primary herpetic gingivostomatitis is characterized by a prodromal of fever followed by an eruption of painful, ulcerative lesions of the gingiva and mucosa, and often, perioral, vesicular lesions. Purpose: The case reported management of acute primary herpetic gingiva-stomatitis in a 6 years old boy. Case: A 6-year-old boy with complaints of difficulty eating or drinking due to pain associated with multiple ulcers in the oral cavity and lips. Patient have been living in boarding school since 6 months ago and was complained of stomatitis which have occurred 4 days ago followed by fever and malaise. Case Management: The patient was instructed to eat nutritious (high calorie and protein diet), soft, blend diet and the following medications were prescribed: (1) antiviral drug (Acyclovir ${ }^{\circledR}$ tablet 200mg) for four times a day; (2) topical hyaluronic acid gel (Aloclair ${ }^{\circledR}$ gel $8 \mathrm{ml}$ ) to be applied on lesions; (3) mouthwash containing benzydamine hydrochloride (Tantum Verde ${ }^{\circledR} 15 \mathrm{ml}$ ) for three times a day; and (4) multivitamin syrup for three times a day. Conclusion: The case reported that the drugs treatment was used according to the severity of HSV-1 infection and patient's symptoms of acute primary herpetic gingiva-stomatitis. Providing supportive care and educating about transmission of the virus are important aspects of nursing care.
\end{abstract}

Keywords: Acute primary herpetic gingivo-stomatitis; HSV-1; children

Correspondence: Tania Saskianti; Department of Pediatric Dentistry, Faculty of Dental Medicine, Universitas Airlangga; J1. Prof. Dr. Moestopo 47 Surabaya 60132 Indonesia; Email: tania-s@fkg.unair.ac.id.

\section{INTRODUCTION}

Acute primary herpetic gingivostomatitis is the symptomatic presentation of the initial exposure to the herpes simplex virus 1 (HSV-1). ${ }^{1}$ The clinical condition of acute primary herpetic gingivostomatitis is characterized by a prodromal of fever followed by an eruption of painful, ulcerative lesions of the gingiva and mucosa, and often, perioral, vesicular lesions. ${ }^{2}$ The age of primary herpetic gingivostomatitis can occur twice, namely the first onset occurs in children aged between 6 months to 6 years and the second onset occurs in the early age of 20 or adult. ${ }^{1,3}$

The initial infection in the majority of patients is subclinical; however, up to $30 \%$ of children develop acute gingivostomatitis. It develops approximately 1 week after initial contact with an infected, often asymptomatic child or adult. ${ }^{1}$ Asymptomatic primary infection are thought to occur in cases in which herpes simplex virus causes minimal epithelial cell destruction through replication. Some studies suggest that only $10-20 \%$ of infected children have severe symptoms and clinical signs. The severity of the primary infection depends on the virus penetrates through the desintegration of epithelial cells, replicating, causing cell damage. The body's natural inflammatory response that is triggered by viral replication also has a bearing on disease progression. ${ }^{4}$ The case reported management of acute primary herpetic gingiva-stomatitis in a 6 years old boy.

\section{CASE}

A 6-year-old male child was brought by parents to pediatric dental specialist clinic at the Dental Hospital of Universitas Airlangga with complaints of difficulty eating or drinking due to pain associated with multiple ulcers in the oral cavity and lips. Patient have been living in boarding school since 6 months ago and was complained of stomatitis which have occurred 4 days ago followed by fever and malaise. General practitioner prescribed paracetamol and multivitamins. On extraraoral examination, there were small vesicles clustered on the lips (commisure and white roll on the right) and multiple ulcers on the lips (left and 
vermillion commissures), approximately $2 \mathrm{~mm}$ and $5 \mathrm{~mm}$ in diameter, irregular edges surrounded by erythematous areas. Intraoral examination showed on the tongue and palatal there are also ulceration, irregular edges, surrounded by erythematous halo, white ulcer base ulcers, diameter of 2 $\mathrm{mm}$ on lateral tongue dan palatal region, enlargement and erithematous on all linear gingival margins. The patient's parents also complained about his bad breath during this period due to poor oral hygiene. Submandibular lymphatic glands were enlarged and general condition of the patient was weak. Family history was unremarkable. According history and clinical findings, the diagnosis is acute primary herpetic gingivostomatitis. Patient profile (Figure 1 and 2) for the first visit.

\section{CASE MANAGEMENT}

The patient was instructed to eat nutritious (high calorie and protein diet), soft, blend diet and the following medications were prescribed: (1) antiviral drug (Acyclovir ${ }^{\circledR}$ tablet $200 \mathrm{mg}$ ) for four times a day; (2) topical hyaluronic acid gel (Aloclair ${ }^{\circledR}$ gel $8 \mathrm{ml}$ ) to be applied on lesions; (3) mouthwash containing benzydamine hydrochloride (Tantum Verde ${ }^{\circledR}$ $15 \mathrm{ml}$ ) for three times a day; and (4) multivitamin syrup for three times a day. The condition is highly contagious, so they were briefed about transmission of the virus. A recall appointment for one week was given for assessment and further treatment. After one week, the patient responded well to the medication and complete healing was seen (Figure 3).

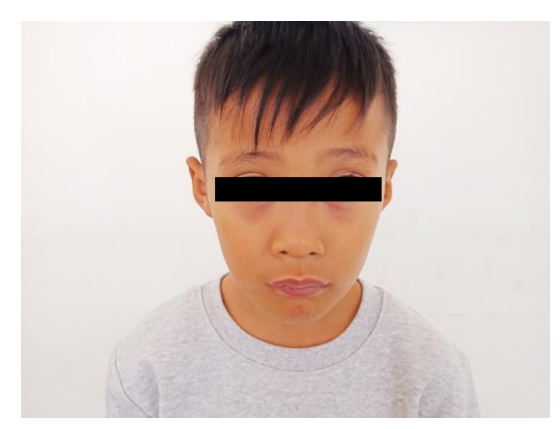

Figure 1. Patient's profile.

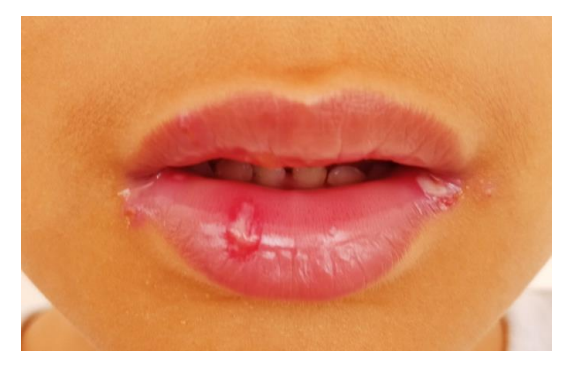

Figure 2. Clinical finding on first visit: small vesicles clustered on the lips and 3 multiple ulcers on the lips, approximately $2 \mathrm{~mm}$ and $5 \mathrm{~mm}$ in diameter, irregular edges surrounded by erythematous area.

\section{DISCUSSION}

Acute primary herpetic gingivostomatitis typically affects children, but rarely, this infection also occurs in adults. The diagnosis of acute primary herpetic gingivostomatitis is generally defined by the clinical data, and no confirmative tests are necessary. ${ }^{5}$ Acute primary herpetic gingivostomatitis is the most common pattern of symptomatic primary herpetic infection, and in the majority of cases, it is related to HSV-1 infection. ${ }^{6}$

The severity of signs and symptoms may be attributable to the virulence of the specific strain of HSV and the host's immune response. Once HSV penetrates the host's epithelial cells, viral replication occurs. The newly formed HSV come into contact with sensory nerve endings and are transported to the corresponding ganglion. In oral labial herpes, the most common site is the trigeminal ganglion. Here the viral DNA enters the ganglion, where it becomes inactive or latent. The incubation period is the period during which viral replication and transport to the sensory ganglion occur. For HSV, this period is variable and can range from a few days to 3 weeks, but in most cases it is approximately 1 week. ${ }^{1,7}$

Clinically, HSV-1 infections begin with prodromal symptoms of fever, loss of appetite, malaise and myalgia. Within few days of prodromal symptoms, erythema and clusters of vesicles and/or ulcers appear on the hard palate, attached gingival and dorsum of tongue and non-keratinized mucosa of buccal and labial mucosa, ventral tongue and soft palate. Vesicles break down to form ulcers that are usually 1-5 $\mathrm{mm}$ and coalesce to form larger ulcers with scalloped borders and marked surrounding erythema. The gingiva is often fiery red, and the mouth is extremely painful, causing difficulty in eating. ${ }^{5-7}$

Management of primary herpetic gingivostomatitis in children is determined by a detailed history and clinical examination to eliminate the differential diagnosis so that it can diagnose and provide appropriate therapy and treatment of drugs according to the severity of herpes simplex virus type 1 infection. Clinical condition and symptoms of the patient greatly influences the selection of drugs to be given. In this case the patient's condition in acute phase. The treatment is a combination of palliative and supportive therapy, consisting of controlling pain and

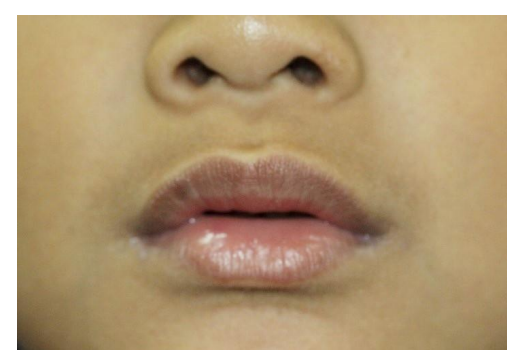

Figure 3. Clinical finding on second visit: the whole ulcers has healed, no scar and pain on the lips. 
Indonesian Journal of Dental Medicine Volume 2 Issue 2 2019; 29-31

fever, preventing dehydration, and shortening the duration of lesions even though orolabial herpetic infections are usually self-limiting. . $^{1,5}$

Acyclovir is a well-established antiviral drug used effectively for the treatment of herpes simplex infections in children. ${ }^{9}$ It reduce the duration of herpes lesions by holding viral DNA polymeration so that viral multiplication is inhibited and, the acute episode lasts shorter so that pain relief is caused by infection. Topical hyaluronic acid gel acts as an anti-inflammatory and maintains wound moisture so that it helps in the healing process. A multivitamin to increase the patient's endurance and mouthwash with an analgesic content to reduce pain and maintain the oral hygiene. Providing supportive therapies such as highcalorie and protein diet of soft foods. ${ }^{10-12}$ Intraoral cleaning with gauze and saline was recommended to eliminate the possibility of fungal contamination, ${ }^{12}$ but in this case the patient has difficulty opening his mouth.

Herpes simplex virus infection is transmitted from person to person when vulnerable individuals have direct physical contact with an infected person. HSV-1 is transmitted through oral-to-oral contact, through contact with the HSV-1 virus in lesions, saliva and mucosal surfaces of the oral cavity and can be transmitted from exchanging cutlery. ${ }^{1,8,13}$ In this case the patient lives in boarding school, which has living an environment that has high tendency to contract viral infections one person to another one. Parents were informed that this disease is contagious so that patient is expected to be isolated from family members or others during the infectious phase. Furthermore, patient is asked to better maintains his healthy body by eating nutritious foods, maintains personal hygiene by washing hands and not sharing cutlery or toiletries with friends. The case reported that the drugs treatment was used according to the severity of HSV-1 infection and patient's symptoms of acute primary herpetic gingiva-stomatitis. Providing supportive care and educating about transmission of the virus are important aspects of nursing care.

\section{REFERENCES}

1. Elizabeth P, J YA. Oral Pathology in the Pediatric Patient A Clinical Guide to the Diagnosis and Treatment of Mucosal Lesions. Switzerland: Springer International Publishing; 2017. 34 p.

2. Aslanova M, Ali R, Zito PM. Herpetic Gingivostomatitis. StatPearls. StatPearls Publishing; 2020.

3. Dantas Martins HD, Sarmento Pinto P, Candeia Lyra T, Nicolau Ferreira VY, Ferreti Bonan PR. Acute herpetic gingivostomatitis in adult patients. Rev Cubana Estomatol. 2018;55(4):1-6.

4. Chauvin PJ, Ajar AH. Acute herpetic gingivostomatitis in adults: a review of 13 cases, including diagnosis and management. J Can Dent Assoc. 2002;68(4):247-51.

5. Turton M. A Case Report on Symptomatic Primary Herpetic Gingivostomatitis. J Dent Heal Oral Disord Ther. 2017 Dec $29 ; 8(8)$.

6. Mohan RPS, Verma S, Singh U, Agarwal N. Acute primary herpetic gingivostomatitis. BMJ Case Rep. 2013 Jul 8;2013.

7. Kolokotronis A, Doumas S. Herpes simplex virus infection, with particular reference to the progression and complications of primary herpetic gingivostomatitis. Vol. 12, Clinical Microbiology and Infection.2006. p. 202-11.

8. Amir J, Harel L, Smetana Z, Varsano I. The natural history of primary herpes simplex type 1 gingivostomatitis in children. Pediatr Dermatol. 1999 Jul;16(4):259-63.

9. Goldman RD. Acyclovir for herpetic gingivostomatitis in children. Can Fam Physician. 2016 May;62(5):403-4.

10. Anggun Mauliana Putri A, Rahmayanti F. Management of Acute (Primary) Herpetic Gingivostomatitis in Immunocompetent Adult Patient: A Case Report. 2018;8(Idcsu 2017):30-3.

11. Singh A, Jayam C, Resident J, Professor A, Author C. Journal of Advanced Medical and Dental Sciences Research Vol. 6, Issue 4. J Adv Med Dent Scie Res. 2018;6(4):127-9.

12. Correia Fontes L de B. Acute Primary Herpetic Gingivostomatitis In A Child: Strategies for Pain Suppression and to Improve Oral Intake. Interv Pediatr Dent Open Access J. 2019 Jul 23;3(1).

13. World Health Organization. Herpes simplex virus. Factsheet of World Health Organization [Internet]. 2019. Available from: https://www.who.int/news-room/fact-sheets/detail/ herpes-simplex-virus 